\title{
Concurrent Hairy Cell Leukemia and Chronic Lymphocytic Leukemia: Diagnostic and Therapeutic Implications
}

Sir,

Coexistence of two separate monoclonal hematological cancers poses challenges both from the diagnostic as well as therapeutic perspectives. We describe the concurrent hairy cell leukemia (HCL) and chronic lymphocytic leukemia (CLL) in a previously healthy person.

A 68-year-old male presented with bicytopenia and $7 \mathrm{~cm}$ splenomegaly. There were no B-symptoms, jaundice, or lymphadenopathy. Complete blood count showed a hemoglobin of $6 \mathrm{~g} / \mathrm{dl}$, total WBC count $8100 / \mathrm{mm}^{3}$, neutrophils $9 \%$, lymphocytes $90 \%$, and platelets $28000 / \mathrm{mm}^{3}$. Direct Coombs test was negative. Peripheral smear examination confirmed lymphocytosis with numerous small mature lymphocytes with clumped chromatin, many smudge cells and a few medium-sized lymphocytes with indistinct nucleoli, weakly basophilic cytoplasm, and irregular "hairy" margins [Figure 1a and b]. Immunophenotyping revealed lymphocytosis with $8 \%$ of cells strongly expressing CD25, CD11c, CD103, and CD123, characteristic of HCL. However, $70 \%$ of lymphocytes were positive for CD5, CD23, CD79b, SMIg and negative for FMC-7, typical of CLL [Figure 1c]. Trephine biopsy showed hypercellular marrow with lymphoid infiltration comprising of widely spaced mononuclear cells surrounded by clear spaces ("fried egg" appearance) consistent with HCL [Figure 1d].

In the absence of leukocytosis and diffuse marrow infiltration, his CLL was considered to be of Binet stage $\mathrm{A}$ and hence not warranting treatment. Bicytopenia and splenomegaly were attributed to HCL, which was treated with cladribine $0.14 \mathrm{mg} / \mathrm{kg} /$ day infusion over $2 \mathrm{~h}$ for 5 consecutive days. Three months later, the patient was asymptomatic with no splenomegaly, hemoglobin $12 \mathrm{~g} / \mathrm{dl}$, WBC $6800 / \mathrm{mm}^{3}$, neutrophils $19 \%$, lymphocytes $74 \%$, monocytes $2 \%$, and platelets $202000 / \mathrm{mm}^{3}$. Peripheral smear [Figure 1e] and flow cytometry [Figure 1f] confirmed total disappearance of HCL clone and persistence of CLL. Patient continues to have no indication for treatment of CLL and will be monitored regularly.

CLL is the most common hematological cancer and can be found incidentally in conjunction with other clonal malignancies. Coexistence of CLL with mantle cell lymphoma and melanoma in a lymph node has previously been reported ${ }^{[1]}$ In a large retrospective review of 270 patients with CLL, Giné et al. had identified 3 cases of concurrent HCL. ${ }^{[2]}$ Optimal evaluation of peripheral smear morphology can help to suspect such a dual diagnosis. The additional investigations such as flow cytometry, bone marrow biopsy, and immunoglobulin chain rearrangement studies should be used appropriately to confirm the same. In most such patients, CLL is not the cause for the clinical features, and hence, priority should be to treat the coexistent HCL.

Financial support and sponsorship

Nil.

\section{Conflicts of interest}

There are no conflicts of interest. 


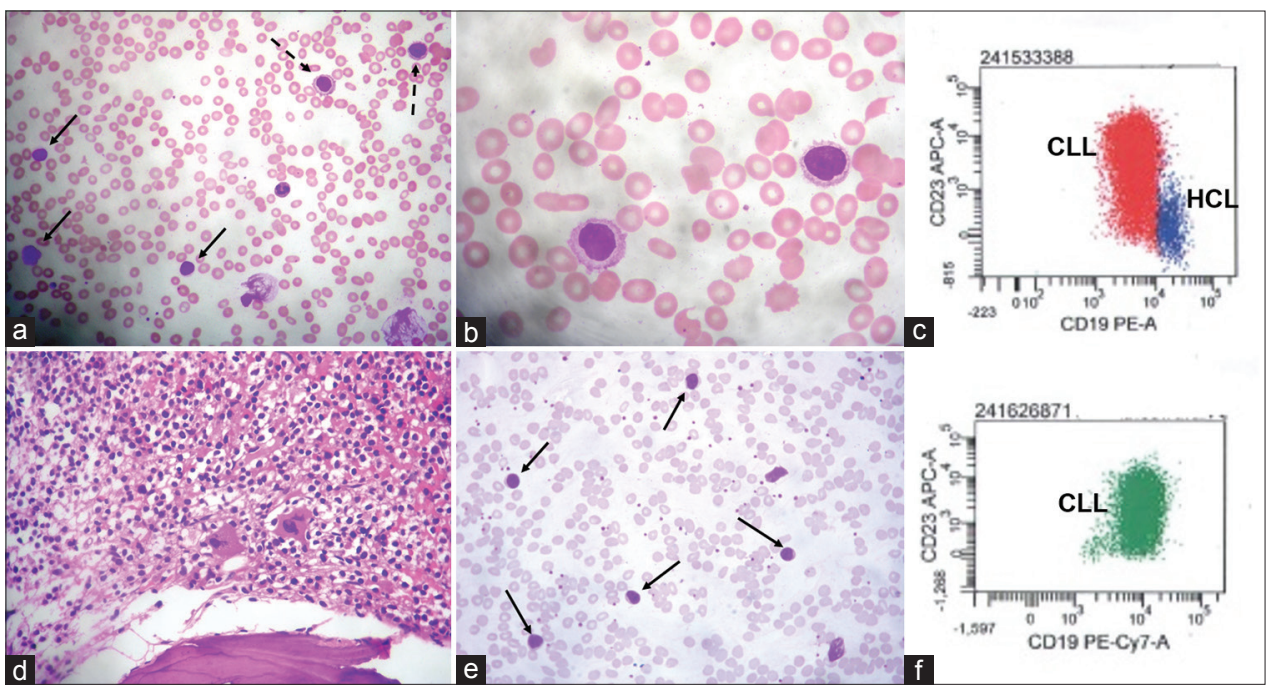

Figure 1: (a) Peripheral smear with 3 chronic lymphocytic leukemia cells (solid arrows), 2 hairy cells (dashed arrows), 2 smudge cells, and severe thrombocytopenia (b) higher magnification of the 2 hairy cells (c) distinct chronic lymphocytic leukemia and hairy cell leukemia clonal population on flow cytometry (d) trephine biopsy demonstrating typical "fried egg" appearance of hairy cell leukemia and diffuse infiltration by chronic lymphocytic leukemia (e) peripheral smear 3 months after cladribine treatment, showing persistence of chronic lymphocytic leukemia cells (solid arrows), disappearance of hairy cells and normal platelet count (f) flow cytometry 3 months after cladribine treatment, showing complete resolution of hairy cell leukemia clone

\section{Parameswaran Anoop, Channappa N. Patil, Venkatachalam Sandhya', Sonal Dhande, Kalpana Janardan ${ }^{2}$, Shivali Ahlawat ${ }^{3}$}

Departments of Hemato-Oncology, ${ }^{1}$ Pathology and ${ }^{2}$ Internal Medicine, Apollo Hospitals, Bengaluru, Karnataka, ${ }^{3}$ Department of Hematopathology, Oncquest Laboratories, New Delhi, India

Address for correspondence: Dr. Parameswaran Anoop, Consultant Hematologist, Apollo Hospitals, 154/11, Opposite IIM, Bannerghatta Road, Bangalore - 560 076, Karnataka, India. E-mail: aparan@doctors.org.uk

\section{References}

1. Addada J, Anoop P, Swansbury JG, Wotherspoon A, Thomas JM, Matutes E, et al. Synchronous mantle cell lymphoma, chronic lymphocytic leukaemia and melanoma in a single lymph node. Acta Haematol 2010;123:194-6.

2. Giné E, Bosch F, Villamor N, Rozman M, Colomer D, López-Guillermo A, et al. Simultaneous diagnosis of hairy cell leukemia and chronic lymphocytic leukemia/small lymphocytic lymphoma: A frequent association? Leukemia 2002;16:1454-9.
This is an open access journal, and articles are distributed under the terms of the Creative Commons Attribution-NonCommercial-ShareAlike 4.0 License, which allows others to remix, tweak, and build upon the work non-commercially, as long as appropriate credit is given and the new creations are licensed under the identical terms.

\begin{tabular}{|l|l|}
\hline \multicolumn{2}{|c|}{ Access this article online } \\
\hline Quick Response Code: & Website: \\
& www.ijmpo.org \\
\cline { 2 - 2 } & DOI: \\
\hline
\end{tabular}

How to cite this article: Anoop P, Patil CN, Sandhya V, Dhande S, Janardan K, Ahlawat S. Concurrent hairy cell leukemia and chronic lymphocytic leukemia: Diagnostic and therapeutic implications. Indian J Med Paediatr Oncol 2018;39:557-8.

() 2018 Indian Journal of Medical and Paediatric Oncology | Published by Wolters Kluwer - Medknow 